\section{A Colônia enferma e a saúde dos povos: a medicina das 'luzes' e as informações sobre as enfermidades da América portuguesa}

The ailing colony and the health of the people: the medicine of the Enlightenment and information about the infirmities in Portugal's American colonies

Jean Luiz Neves Abreu

Núcleo de Estudos Históricos e Territoriais Universidade do Vale do Rio Doce Rua Vasco Fernandes, 169 B Morada do Vale 35057-710 Governador Valadares - MG - Brasil jluizna@hotmail.com
ABREU, Jean Luiz Neves. A Colônia enferma e a saúde dos povos: a medicina das 'luzes' e as informações sobre as enfermidades da América portuguesa. História, Ciências, Saúde - Manguinhos, Rio de Janeiro, v.14, n.3, p.761-778, jul.-set. 2007.

Os avanços da medicina no conhecimento do corpo humano e nas formas de tratar as enfermidades não tiveram impacto somente sobre o corpo individual. A partir do século das luzes a medicina passou a se preocupar cada vez mais com a 'saúde dos povos'. Os conhecimentos oriundos de novas teorias médicas passaram a ser postos a serviço do Estado, possibilitando formas mais eficazes de diminuir as epidemias e a alta mortalidade. Este artigo pretende examinar o significado que tais mudanças na medicina assumiram para o Estado português, abordando seus impactos no universo colonial com base na questão das enfermidades dos negros e do estabelecimento de informações acerca das enfermidades na América portuguesa.

PALAVRAS-CHAVE: 'saúde dos povos'; medicina; enfermidades; Iluminismo.

ABREU, Jean Luiz Neves. The ailing colony and the health of the people: the medicine of the Enlightenment and information about the infirmities in Portugal's American colonies. História, Ciências, Saúde-Manguinhos, Rio de Janeiro, v.14, n.3, p.761-778, July-Sept. 2007.

The progress in medicinal knowledge about the human body and the ways of treating different ailments did not just affect individuals. As of the Enlightenment, medicine started to pay ever greater attention to the 'health of the people'. The knowledge derived from new medical theories started to be put at the State's service, bringing about greater efficiency in reducing epidemics and high death rates. This article seeks to examine the significance of these changes in medicine for the Portuguese State, investigating their impact on the colonies, based on the issue of ailments suffered by blacks and the establishment of information about the ailments suffered in Portugal's colonies in the Americas.

KEYWORDS: 'health of the people'; medicine; ailments; Enlightenment. 


\section{As reformas pombalinas e a saúde dos povos}

$\mathrm{O}$ s avanços da medicina buscando compreender o funcionamento do corpo humano e combater com maior eficácia as enfermidades não tiveram impacto somente sobre o corpo do indivíduo. A partir do século das luzes, a medicina passou a se direcionar cada vez mais para a saúde da população, e os conhecimentos oriundos de novas teorias médicas passaram a ser postos a serviço do Estado. Ao contrário da concepção hipocrática, que propunha compreender a natureza da doença em termos individuais, a racionalidade científica moderna iluminista representa uma inflexão na prática médica, de forma que "o conhecimento dos fenômenos extra-individuais não se presta mais a apenas instruir ações de caráter individual, mas passa a apreender a saúde como fato social ampliando, assim, o campo normativo das ciências médicas" (Ayres, nov. 2001, p.85).

Em Portugal de fins do século XVIII é possível observar que a 'saúde dos povos', termo recorrente em tratados médicos da época, era uma preocupação não circunscrita apenas à população portuguesa, estendendo-se às populações coloniais, sobretudo aos escravos. Entre os diversos aspectos assumidos pelas reformas da medicina em Portugal, este artigo pretende abordar seu impacto no universo colonial, privilegiando a questão das doenças dos negros e das informações acerca das enfermidades na América portuguesa. As próximas páginas apresentam algumas conclusões de uma pesquisa em andamento sobre o saber médico no século XVIII. Nesse sentido, procura-se retomar não só alguns estudos sobre a questão, mas também a análise de tratados médicos e outras fontes, ainda que não sejam primárias.

Os impactos das reformas pombalinas nos domínios do ensino em Portugal já foram sublinhados pela historiografia. Quando Sebastião José de Carvalho e Melo, mais conhecido por marquês de Pombal, assumiu a Secretaria de Negócios Estrangeiros e Guerra, não realizou apenas reformas de âmbito administrativo e econômico. Suas medidas estenderam-se também ao universo da ciência em Portugal, até então dominada pela escolástica e pela influência dos jesuítas. A partir da década de 1770, por meio das mudanças do ensino e da criação de novas instalações universitárias, Pombal procurou difundir as 'luzes' européias no Reino. A introdução de princípios norteadores da ciência moderna realizou-se na Universidade de Coimbra, onde os reformadores procuraram conciliar o progresso científico com o ensino (Falcon, 1982; Carvalho, 1987a, p.423-483; Villalta, 1999, p.142-152).

A reforma pombalina dos estudos superiores distribuiu a Universidade de Coimbra nas Faculdades de Teologia, Cânones, Leis, Medicina, Matemática e Filosofia. Aprovados em agosto de 1772, os 
${ }^{1}$ O currículo do curso de medicina foi alvo de algumas mudanças no ano letivo de 17911792. Com as modificações, transferia-se a cadeira de Anatomia do segundo ano para o primeiro. Avançava para o terceiro ano a cadeira de Matéria Médica e Farmácia, permanecendo os dois últimos anos do curso sem modificações. O propósito do novo quadro curricular era adequar o ensino da medicina ao próprio ato médico.

Privilegiava-se, em um primeiro

momento, o conhecimento do corpo e a localização espacial da doença; em segundo lugar, destacava-se o conhecimento da gênese e do desenvolvimento das doenças e, finalmente, davam-se a conhecer os medicamentos utilizados, bem como os modos de sua preparação (Crespo, 1990, p.81-82).
Estatutos da Universidade dedicavam o terceiro capítulo à Faculdade de Medicina. Com o intuito de aplicar à medicina os princípios que norteavam ciências como a física e a química, o documento enfatizava o estudo da "medicina empírico-racional", para a qual as luzes da teoria seriam úteis para se poderem ler sem equívoco as verdades que ensina "o magistério da natureza". As "observações bem feitas, examinadas e comparadas", seriam úteis para "retificar, verificar, ampliar, limitar, e aperfeiçoar os conhecimentos da teoria" (Estatutos..., 1972, p.18). Nesses termos, o documento dos Estatutos procurava romper com o predomínio da cultura livresca e do 'maravilhoso' que predominava na medicina. Afinal, à época, o saber médico em Portugal era baseado ainda em autores da Antiguidade como Hipócrates e Galeno e marcado pela influência das crenças astrológicas e mágicas. Dessa forma, a medicina mantinhase relativamente afastada das inovações do restante da Europa (cf. Ribeiro, 1997).

Para atualizar o conhecimento médico no Reino foi necessário reformular o próprio curso de medicina. De início eram exigidas certas habilitações aos estudantes, como o conhecimento do latim, grego e filosofia. Em seguida, vinha o curso preparatório de três anos, durante os quais os alunos freqüentavam as disciplinas de geometria, história natural, cálculo, física experimental, fronomia - ciência completa dos movimentos - e química. No primeiro ano do curso propriamente dito, o aluno estudaria a 'matéria médica', constituída pela história da medicina, e a análise das propriedades de diversas plantas e raízes. O segundo era dedicado inteiramente à 'anatomia', com aulas práticas no hospital escolar. $\mathrm{O}$ terceiro ano ocupava-se das 'instituições médicas', constituídas pela medicina teórica, fisiologia, patologia, semiologia, higiene e terapêutica. $\mathrm{O}$ quarto ano era dedicado aos aforismos de Hipócrates e Boerhaave, e o quinto dedicado inteiramente ao ensino clínico da medicina e à prática no hospital. ${ }^{1}$

A química e a botânica passaram a ser cada vez mais valorizadas como conhecimentos auxiliares dos estudos médicos. Na esteira da relevância adquirida por essas disciplinas estava a consagração de nomes como Newton, na física; Harvey, na anatomia; Boerhaave, em patologia; e de Van Swieten, em farmacologia, entre outros que renovaram a medicina européia (Maxwell, 1996, p.11). Além desses aspectos, os Estatutos determinavam também a construção de laboratórios e estabelecimentos para que os alunos pudessem pôr em prática as teorias. Para a prática da medicina e da cirurgia foi criado o 'hospital escolar', onde se situavam o 'teatro anatômico' e o 'dispensário farmacêutico', destinado também à formação de boticários (Carvalho, 1987a, p.218).

Com base na leitura dos autores 'modernos', dos laboratórios e da prática hospitalar, procurava-se aperfeiçoar a formação aos es- 
tudantes de medicina, preparando-os melhor para enfrentar as doenças. Além dessa finalidade, a saúde das populações passou também a se incorporar de forma efetiva no horizonte do saber médico. Embora nos anos anteriores às reformas pombalinas essas questões não fossem desconsideradas, data de fins do século XVIII a integração da medicina preventiva às disciplinas e à comunidade médica, uma das tendências da medicina de cunho iluminista (Pita, 1996, p.33-34).

O principal obstáculo a ser superado nesse sentido diz respeito à precariedade da assistência médica. Em seu Suplemento à história da cirurgia, no qual trata do estado da cirurgia em Portugal, o médico português José Manoel Leitão, autor de obra sobre a história da anatomia e cirurgia em Portugal, denunciava não haver cirurgiões "para as expedições das frotas comerciais e para o socorro das províncias, onde já não havia senão barbeiros que sangravam e meros curandeiros" (Leitão, 1788, p.365). Com o intuito de diminuir esses problemas, desde o consulado pombalino o Estado português procurou prover as suas colônias de médicos e cirurgiões. Ao se referir aos cirurgiões formados na Universidade de Coimbra, Manoel José Leitão afirmava que o

ministério conhecendo a utilidade vantajosa que têm produzido estes novos cirurgiões, não hesitou em preferi-los aos partidos que ele mesmo promove nos exércitos, armadas e conquistas, em cujas capitais os tem estabelecido, não só com obrigações de curar nos hospitais caritativos e militares, mas também de ensinarem anatomia (Leitão, 1788, p.362-363).

Um dos objetivos das autoridades era, portanto, formar um corpo de cirurgiões para atuar nos domínios ultramarinos. Manoel José Leitão cita como exemplos os nomes de Francisco Manoel Barroso, "cirurgião-mor do Estado de Goa e Índia" e Manoel Antônio, "cirurgião de Banguela, na Costa da África, e professor de anatomia naquela capital" (Leitão, 1788, p.363). Outra meta era a regulamentação e melhor fiscalização dos ofícios relacionados à arte de curar, já que predominava a atuação de empíricos e curandeiros. Com esse objetivo d. Maria I instituiu, em 1782, a Junta do Protomedicato "composto de sete deputados, cinco médicos e dois cirurgiões com dois secretários, um que pertence à repartição da medicina e outro da cirurgia" (p.363). O órgão, que funcionou no Brasil até 1808, quando foi substituído pela Fisicatura (Pimenta, 2003, p.307), tinha como principal função exercer com maior vigor a fiscalização sobre os ofícios de curar, praticados sem licença e clandestinamente. Embora com a criação da Junta do Protomedicato não se possa falar de uma mudança concreta no tocante à assistência médica na América portuguesa, é possível observar um maior registro das cartas de diversas categorias na área de saúde (Ribeiro, 
1997, p.127-128). Tão importante quanto garantir a assistência médica era coibir os excessos de terapias existentes. Com essa finalidade, a Farmacopéia geral para o reino e domínios de Portugal, de 1794, visava regulamentar a desordem existente nas boticas, proibindo a produção de medicamentos a partir de outras farmacopéias (Pita, 1999, p.65-66). Desde que a questão da assistência médica se faz presente em estudos sobre a medicina na América portuguesa, importa abordar melhor um outro aspecto desse problema, relacionado às formas pelas quais se propunha resolver as questões da saúde na esfera pública. Com a reforma dos Estatutos da Universidade passava a haver uma consciência mais nítida da importância da prevenção das enfermidades. Daí o papel dedicado, nos Estatutos, à higiene:

A higiene também é um corolário da fisiologia: porque das causas, e efeitos da vida, e da saúde resultam o conhecimento dos meios, que se hão de aplicar para a conservação delas. Esta é a parte mais importante da medicina, e que infelizmente tem sido pouco cultivada pelos modernos (Estatutos..., 1972, p.53).

A relevância atribuída à higiene reforçava os argumentos da obra Tratado da conservação da saúde dos povos, cujo objetivo principal era "mostrar a necessidade que tem cada Estado de leis e de regramentos para preservar-se de muitas doenças, e conservar a saúde dos súditos" (Sanches, 1757, p.VI). De autoria do 'estrangeirado' Ribeiro Sanches, que por sua condição de cristão-novo viveu boa parte de sua vida fora de Portugal, tendo porém contribuído para a renovação do ensino médico nesse país (Araújo, 1984, p.377-395), o livro pode ser considerado um marco da literatura higienista portuguesa em que aflora a articulação entre o poder científico e técnico da medicina (Pita, 1996, p.437). Ribeiro Sanches propõe uma série de medidas para conservar a saúde da população nos navios, hospitais, prisões e povoações, locais onde se propagavam as doenças. O projeto de Ribeiro Sanches previa também medidas que deveriam ser aplicadas à higienização das cidades: seria "lei inviolável que cada morador tivesse de limpar pela manhã a fronteira da sua casa". Haveria também certo número de carros para transporte das lamas e imundícies. Não se admitiria nenhum "ofício que causasse podridão ou mau cheiro", de forma que os carniceiros, curtidores, vendedores de peixe e queijos vivessem em locais mais afastados (Sanches, 1757, p.79-80).

A obra de Ribeiro Sanches nos é útil como referência de uma literatura médica que circulava com mais intensidade em Portugal e nos domínios ultramarinos em fins do século XVIII, aquela destinada a divulgar preceitos de medicina e higiene (Marques, 2004, p.43-44). Nas últimas décadas do século XVIII, com a publicação de um número cada vez maior de manuais médicos estrangeiros com 
2 Veja-se o caso do tratado de Francisco da Fonseca

Henriques, Âncora medicinal para

conservar a vida com saúde, publicado na década de 1720. A obra direcionava-se à população, conforme afirmava seu autor: "Inclui este livro um tratado de alimentos, coisa muito necessária para os que não são médicos, porque é razoável que saiba cada qual que alimentos usa sem mendigar de notícias alheias" (Henriques, 2004, p.18). essas características, o saber médico assumiu uma feição explicitamente pedagógica e preventiva. Essa tendência do pensamento médico pode ser identificada no Aviso ao povo sobre a sua saúde, de Tissot. Consciente das dificuldades de fazer o conhecimento médico chegar a todos, o médico francês endereçava sua obra aos mestres de escolas, parteiras, cirurgiões das aldeias, que poderiam "tirar partido desta obra" e fazer com que seus conselhos se multiplicassem (Tissot, 1773, t.I, p.19). Em acordo com tais princípios foi publicado, em 1788, Medicina doméstica ou tratado completo dos meios de conservar a saúde e de curar, de autoria do médico Guilherme Buchan. Este afirmava que "a cura das enfermidades é sem dúvida um ponto de grande momento; mas os meios de conservar a saúde e precaver os males são de maior importância" (Buchan, 1788, t.I, p.LXVI).

Ao lado dos tratados de médicos estrangeiros, outros títulos publicados por médicos portugueses e luso-brasileiros eram endereçados às famílias, incluindo temas como os cuidados com a saúde das mulheres e das crianças e as formas pelas quais se poderiam prevenir as enfermidades. Ainda que tais aspectos não eram desconsiderados nos tratados médicos anteriores ${ }^{2}$, a partir de então eles passaram a ser postos em primeiro plano. O Tratado de educação fysica dos meninos para uso da nação Portuguesa, de 1790, de autoria do médico luso-brasileiro Francisco de Mello Franco, é exemplo de obra destinada a tais questões. Esse também seria o título da obra do médico Francisco José de Almeida (1791), que abordava temas análogos. Com contornos pedagógicos explícitos, essas obras revelam ser produtos de "médicos preocupados com a saúde das populações mas, também, dominados por preocupações didáticas, que julgavam ser necessárias para maior eficácia de sua intervenção" (Crespo, 1990, p.547). Em um contexto em que a prevenção assumia cada vez maior importância, esses tratados davam conselhos úteis a fim de servir de guias de medicina no cotidiano, sendo usados por cirurgiões, empíricos e pelas mais diversas pessoas, em um processo maior de difusão dos impressos (Marques, 2004).

Ao considerar a mensagem de médicos como Ribeiro Sanches e Francisco de Mello Franco, entre outros títulos que circulavam em Portugal e na América portuguesa, é possível perceber que, a exemplo do que acontecia em outros territórios da Europa, também em Portugal a saúde e a doença como fato de grupo e de população eram problematizadas no Setecentos. Desempenhando o papel de técnica geral da saúde, a medicina adquire um lugar importante na maquinaria do poder. Os médicos passam a intervir em diversas esferas, estabelecendo topografias sobre a saúde da população, suas formas gerais de existência e de comportamento. Tais questões nos remetem às análises de Michel Foucault (2001), segundo o qual uma das características da medicina do século XVIII é representada pela totalização do olhar médico, que procurava apreender os fenô- 
menos epidêmicos e sua relação com as condições de vida das populações (p.28-35).

No caso de Portugal e da América portuguesa é preciso considerar os limites dessas topografias médicas, já que os mecanismos para inventariar a saúde da população eram ainda precários. Embora tenha suas manifestações no século XVIII, a existência de uma 'política de saúde' em Portugal de forma mais eficaz só ocorreu no século XIX. A Academia de Ciências de Lisboa publicou, em 1814, um programa de elaboração de topografias médicas seguindo as recomendações da Societé Royale de Médicine, de Paris. Entre os objetivos desse programa estava a implantação dos mecanismos de controle de saúde dos portugueses. O Protomedicato, órgão que até então regulamentava e fiscalizava a arte médica, foi substituído, em 1813, pela Junta da Saúde Pública (Crespo, 1990, p.21-53).

Apesar da dificuldade de estabelecer uma 'política de saúde' destinada às populações, não se pode desconsiderar os esforços do governo português no sentido de direcionar investimentos para esse fim. Além da já mencionada publicação de obras destinadas à prevenção das enfermidades, havia o interesse em obter informações sobre as enfermidades que proliferavam na América portuguesa e resultavam na diminuição do número de colonos e escravos.

\section{A saúde dos escravos: uma questão do Estado}

Para os Impérios coloniais, o problema das doenças que atingiam os escravos era algo com que cotidianamente deparavam os senhores. Em vista disso, uma série de obras dedicadas à administração de escravos - tratados de história natural, memórias econômicas, manuais de agronomia - foi publicada com vistas a implementar uma moderna gestão da mão-de-obra escravista em convergência com a Ilustração. Nesse contexto, conforme observou Rafael de Bívar Marquese (2004), o saber médico adquiria um papel extremamente relevante. Este era "encarado como um instrumento fundamental ao desenvolvimento colonial, dada a percepção do impacto que as doenças tropicais causavam na população branca e nos escravos" (p.98). Marquese cita o caso do tratado médico de Jean-Barthélemy Dazille, Observation sur les maladies des nègres, publicado em 1776, que se enquadrava nas reformas que o governo francês procurava colocar em prática, conectando o saber médico ao poder público. Dazille foi, nesse sentido, um funcionário a serviço do governo francês, trabalhando em Caiena e na ilha de Bourbon (oceano Índico). Ao longo de sua estadia, esse médico estudou as condições sanitárias a que os escravos estavam submetidos e publicou outras duas obras sobre o tema: Observations génerales sur les maladies des climats chauds (1785) e Observation sur les tétanos (1788) (Marquese, 2004, p.98-99). 
A questão da produtividade escravista era central na obra de Dazille, que estabelecia uma correspondência entre a riqueza das colônias e a população abundante de negros:

A população das colônias determina-lhes o grau de prosperidade. Se ela é numerosa produz força, e riqueza; se fraca, ou medíocre, ela indica pobreza e frouxidão ... Não é especialmente senão em uma população abundante de negros, que as colônias acham a origem primitiva de sua opulência; porque sem os negros nada de cultura, nada de produtos, nada de riquezas (Dazille, 1801, p.15).

Se a obra de Dazille era importante para o governo francês diminuir a mortalidade entre os negros, é necessário sublinhar igualmente seu significado para Portugal. Os benefícios que se poderiam obter pelo conhecimento das causas e da cura das enfermidades dos negros seriam uma das explicações que levaram José Vieira de Carvalho, que exerceu o ofício de cirurgião-mor do Regimento da Cavalaria Regular da Capitania de Minas Gerais, a traduzir a obra do médico francês, publicando-a em 1801. No prefácio à obra, José Vieira de Carvalho enfatizava, a exemplo do que ocorria nas Antilhas francesas, que a mortalidade dos negros levava embora a riqueza metropolitana:

A mudança de clima, a diferença de tratamento, um trabalho contínuo, e desmedido, e até a fome raríssimas vezes interrompida, juntos à triste consideração de seu penoso estado, são outras e tantas causas das singulares e gravíssimas enfermidades, a que é sujeita entre nós esta raça desaventurada de homens, e que fazendo-lhes a vida pesada, e adiantando-lhes a morte, levam à sepultura o melhor dos cabedais daquela e das outras colônias da América portuguesa; enterrando com eles o mesmo ouro, que os seus braços haviam desenterrado, e secando assim na origem um de seus primeiros mananciais das riquezas da Coroa e do Estado (Dazille, 1801, fl.01).

As causas pelas quais faleciam os cativos, detectadas por José Vieira de Carvalho, já haviam sido objeto de observação de cronistas, médicos e cirurgiões que estiveram na América portuguesa. Luís Gomes Ferreira, cirurgião que viveu no início do século XVIII na região das Minas, já fazia notar, no seu tratado médico Erário mineral (1735), que as condições de trabalho, o clima e a alimentação eram as principais causas das enfermidades entre os negros. Em vista disso, dirigindo-se aos senhores de escravos, aconselhava:

E advirto que, se o doente for preto, se lhe dê boa cobertura, casa bem recolhida e o comer de boa substância, que nisto pecam muito os senhores de escravos que hão de dar conta a Deus ... Outrossim, advirto que os senhores vão ver os seus escravos 
${ }^{3} \mathrm{O}$ tema das doenças de escravos no Brasil foi assunto de diversas obras no decorrer do século XVIII, sendo objeto tanto de médicos quanto de moralistas. Os autores eclesiásticos não só justificavam teologicamente a escravidão, como descreviam a melhor forma de 'governar os escravos'. Esses textos expunham uma teoria do governo dos escravos assentada sobre as diretrizes cristãs e eram elaborados com base em convenções intelectuais que combinavam o discurso clássico sobre oikonomia e agronomia com o discurso bíblico das obrigações recíprocas (Marquese, 2004, p.19-86). quando estiverem doentes e lhes façam boa assistência, porque nisto lhes darão muita confiança e consolação, metendo-lhes ânimo e esforço para resistirem melhor à doença ... e assim, por conveniência, como por obrigação, devem tratá-los bem em saúde e melhor nas doenças, não lhes faltando com o necessário, que desta sorte farão o que devem, serão bem servidos, terão menos doenças, mais conveniência, experimentarão menos perdas e terão menos conta que dar no dia delas (Ferreira, 2002, v.1, p.258).

Conforme é possível observar nessa passagem, o cuidado com a saúde dos escravos era uma obrigação, o que se colocava em termos cristãos. Mas era também uma conveniência, já que, agindo de tal forma, os senhores experimentavam menores perdas. Embora Luís Gomes Ferreira refira-se ao fato de que o mau tratamento dos cativos é um pecado - o que revela a influência dos princípios morais na questão ${ }^{3}$ - predomina o argumento de que um escravo doente representaria prejuízo para seu senhor. Era nesse sentido que Gomes Ferreira deplorava os efeitos negativos do escorbuto sobre os habitantes das Minas, pois estes "perdiam escravos sem número [e] os que não perecem de tal doença, lhes fazem grande despesas nas boticas" (Ferreira, 2002, v.2, p.639). Além de sublinhar que o escravo doente era razão de despesas, a presença dos princípios econômicos é perceptível também na observação que o cirurgião fazia aos senhores para a compra de um escravo. Alertava que olhassem se este tinha "joelhos metidos para dentro", porque caso tivesse "algum jeito ou sinal de joelhos inclinados para dentro e para fora, de nenhum modo" o comprassem, "porque, pelo tempo adiante, se lhe vão entortando cada vez mais" (v.1, p.433).

Se, por um lado, as observações de Luís Gomes Ferreira mostram que a enfermidade dos negros afetava a produtividade escravista - o que tornava relevante a intervenção do saber médico por outro é necessário observar que, na obra de Dazille, o tema assumia diferentes desdobramentos. Segundo afirmação do próprio José Vieira de Carvalho, tradutor da obra, a morte dos escravos não só representava prejuízo para os senhores, mas também acabava com um dos primeiros mananciais das riquezas da Coroa, "enterrando com eles o mesmo ouro, que os seus braços haviam desenterrado" (Dazille, 1801, fl. 02). O comentário de José Vieira de Carvalho afinava-se, desse modo, com o pensamento econômico ilustrado adotado no mundo luso-brasileiro pelas elites letradas em fins do Setecentos. Nesse sentido, as reformas econômicas e administrativas que se iniciaram com Pombal estavam atreladas ao desenvolvimento de estudos desenvolvidos pela elite letrada com o propósito de diminuir a alta incidência de mortalidade e enfermidade entre os escravos.

É o caso do estudo publicado, em 1793, pelo luso-brasileiro, que foi membro da Academia Real das Ciências de Lisboa, Luiz Antô- 
nio de Oliveira. Sua Memória a respeito dos escravos e tráfico da escravatura entre a costa d'África e o Brasil tinha o propósito de examinar as causas da elevada mortalidade entre os negros africanos e encontrar soluções para o problema. Além de arrolar as doenças que os atingiam durante a travessia atlântica, o autor propunha certas medidas preventivas, associadas a um melhor tratamento dos escravos - boa alimentação, vestuário, moradia, tempo de descanso e cuidados nas enfermidades - e a certos cuidados nas embarcações embarque de menor número de escravos, mudanças nos navios para aumentar a circulação de ar e embarque de maior quantidade de alimentos e de água (Marquese, 2004, p.182-183).

A publicação de tratados e memórias pelos ilustrados tinha propósito utilitário e econômico, atendendo não apenas aos interesses privados mas também públicos, mas há que considerar que essas informações não podem ser atribuídas somente a um aspecto da Ilustração em Portugal. Sem negar a forma utilitarista que o Iluminismo assumiu naquele contexto, Lorelai Kury (2004, p.111112) - ao enfatizar o papel exercido pela elite ilustrada luso-brasileira no estabelecimento e na divulgação de dados relativos à natureza e à população do Brasil - pondera que o Iluminismo português não deve ser visto como algo isolado, uma vez que a relação entre conhecimento científico e Estado colocava o Reino em sintonia com as políticas administrativas dos demais países europeus, aproximando-o dos sistemas coloniais francês e inglês. Não havia, assim, descompassos qualitativos entre a elite ilustrada luso-brasileira e os homens de ciência do restante da Europa.

Essas observações contribuem para melhor compreensão do papel que assumia, em Portugal, o conhecimento médico de outros países, pois era importante a apropriação de informações e das experiências produzidas em outras colônias com o intuito de diminuir a mortalidade escravista, o que ocorria não só por meio da circulação de obras em outras línguas, em Portugal e na América portuguesa, mas também pela sua tradução para o português. Frei Veloso, por exemplo, traduziu um tratado sobre o uso de plantas medicinais para a cura da lepra entre os escravos do Suriname, visando sua utilidade no tratamento de escravos no Brasil (Dias, 1969, p.142). Traduzindo a obra de Dazille, José Vieira de Carvalho afinava-se, portanto, com o conhecimento médico produzido na Europa. Mostrava estar, assim, atualizado. Além do mais, em sua biblioteca podiam ser encontradas obras como Medicina prática, de Loundry, Medicina doméstica, de Buchan, e a Memória sobre a conservação da saúde dos agricultores, entre outros volumes sobre medicina e arte militar (Inventário..., jul.-dez. 1905, p.706-709).

$\mathrm{O}$ fato é que diversas doenças que acometiam os escravos em outras colônias também eram comuns à América portuguesa. É o caso do escorbuto, também denominado 'mal de Luanda', doença 
que, em decorrência das carências alimentares, causava a morte de inúmeros marinheiros e negros. Dazille (1801) observava que os negros que chegavam às colônias sofriam dessa e de outras enfermidades em virtude da qualidade e quantidade precária dos alimentos e afirmava que a "situação dos negros a bordo é a das mais terríveis" (p.66). Graças às analogias físicas e morais que se podiam estabelecer entre os casos estudados pelo médico francês e as condições de vida dos escravos na América portuguesa, a obra de Dazille servia como um guia prático para José Vieira de Carvalho e revelava-se ainda de grande utilidade para os que possuíam escravos, pois em virtude da "raridade de médicos, fazem que, pela maior parte, o seja cada um em sua casa" (fl. 02).

É por meio dessas observações que as diversas notas e comentários que José Vieira de Carvalho adiciona à edição portuguesa ganham significado. Elas servem de parâmetro para comparar as doenças dos escravos nas colônias francesas com as que se verificavam na América portuguesa. A constatação de que o clima, a alimentação precária e a roupa insuficiente eram as principais causas das enfermidades dos negros em diversas colônias servia como referência para aplicar as terapias empregadas por Dazille à realidade da América portuguesa. Conforme afirmava o próprio Dazille (1801, p.25), o que "nós temos observado em S. Domingos, Cayena ... e outros estabelecimentos, seja na África, na Ásia ou na América, se observa igualmente na ilha de Madagascar". A leitura de obras produzidas no restante da Europa colocava, assim, médicos e cirurgiões no mundo luso-brasileiro em contato com informações da ciência médica mais atualizada do período, principalmente aquela destinada a lidar com as enfermidades em terras tropicais.

\section{Notícias das enfermidades na viagem filosófica de Alexandre Rodrigues Ferreira}

A questão da saúde na América portuguesa não se resumia apenas à população escravista. Afinal, ali proliferavam enfermidades específicas que atingiam grande parte da população, o que tornava necessário conhecer melhor a realidade dos trópicos, bem como as condições de vida dos seus habitantes. Ao direcionar seu olhar para as questões que envolviam a saúde dos trópicos, Ribeiro Sanches já enfatizava o perigo das inundações para a saúde da população que vivia em locais onde elas eram freqüentes:

Tanto em Portugal, em todos os lugares que borda o Tejo, em Angola onde inundam tantos rios naquele reino, como em toda a América, depois das inundações, logo que as matérias das enxurradas começam a apodrecer, o ar infecta-se e produz semelhante podridão nos corpos: manifesta-se por toda a sorte de febres podres, e, sobretudo, por disenterias... (Sanches, 1757, p.46) 
O clima quente também era outro motivo de doenças - realidade comum à África, Índia e América portuguesa. Nos trópicos estavam situadas

as colônias de Portugal depois das ilhas de Cabo Verde até a China: aquelas mais habitadas são as do Maranhão, Brasil, Costa da Mina, Angola, Moçambique, e na Índia: nestes sítios o calor é contínuo; os dias são por todo o ano quase igual à noite ... Desta podridão provêm aquelas febres pestilentas, que chamam carneiradas nas minas do Mato Grosso, Cuiabá, Guaianazes. Da mesma origem vêm outros males tão comuns a todo o Brasil, como são os insetos mais nocivos à saúde, e outras moléstias vulgares. (Sanches, 1757, p.29)

Conforme se constata, os trópicos eram revestidos de um olhar negativo por Ribeiro Sanches. As observações do médico mostram as condições pouco favoráveis à conservação da saúde a que estavam expostos os habitantes da América portuguesa. Entretanto, observações desse gênero não couberam somente aos médicos. Funcionários e viajantes também tinham por tarefa remeter a Portugal informações de toda espécie sobre os territórios que percorriam. Nesse sentido, as viagens filosóficas de fins do século XVIII, além de coleta de espécies ou da exploração dos recursos naturais, cumpriram também outras finalidades. Alguns dos mais célebres viajantes do século das luzes foram médicos, boticários e farmacêuticos, em razão dos laços que, à época, "associavam o ensino das ciências naturais, da botânica, da anatomia comparada e da zoologia ao estudo da medicina" (Bourguet, 1997, p.223).

A partir das reformas pombalinas do ensino, as viagens de caráter científico passaram a ter também uma importância vital para Portugal: deviam garantir a exploração das potencialidades econômicas dos recursos naturais e estabelecer um melhor inventário das informações dos domínios ultramarinos. Em 1783 foram enviados grupos de naturalistas e riscadores para as possessões africanas, Goa e Brasil, para execução de um plano de recolha de materiais de toda ordem que a natureza oferecia. Foi o caso de João da Silva Feijó, enviado para Cabo Verde; de Ângelo Donatti, para Angola; Manuel Galvão da Silva, para Moçambique; e Alexandre Rodrigues Ferreira, para a América portuguesa, onde percorreu as capitanias do Grão-Pará, Rio Negro, Mato Grosso e Cuiabá, entre 1783 e 1792 (Carvalho, 1987b, p.86-87).

A 'viagem filosófica' de Alexandre Rodrigues Ferreira insere-se, portanto, em um processo de conhecimento e exploração do território que percorreu. Destaca-se como esforço de sistematização de informações acerca da população e das riquezas naturais. Além das remessas de exemplares da fauna e flora, o viajante deveria escrever relatórios que seriam enviados à Secretaria do Estado da Marinha 
4 Utilizou-se a edição fac-similar dos volumes XLVIII, n.1, p.1-123, XLIX, n.1, p.123-288, L, n.2, p.11-141 e LI, n.1, p.5166 da Revista do Instituto Histórico e Geográfico Brasileiro, dos anos de 1885, 1886,1887 e 1888 respectivamente, organizada pelo Museu Paraense Emílio Goeldi, em 1983. e Negócios Ultramarinos, por intermédio do capitão geral da província do Rio Negro, João Pereira Caldas. Questões relacionadas aos significados administrativos e científicos da viagem do naturalista são aspectos já discutidos em outros trabalhos (Carvalho, 1987b, p.91-96; Domingues, 2001; Raminelli, dez. 1998). O mesmo não se pode dizer das informações sobre as enfermidades, que merecem ser aqui abordadas. Os comentários a elas relacionados, deixados pelo viajante, demonstram a preocupação em relatar as condições de alimentação e saneamento, o registro das principais doenças e as formas de cura utilizadas pelos habitantes. ${ }^{4}$

Alexandre Rodrigues Ferreira fez diversos apontamentos sobre as causas das doenças que acometiam brancos e índios. Entre as principais constava a qualidade dos alimentos que usavam, "sendo a farinha, o peixe e a tartaruga alimentos de pouca nutrição", o que causava os "vícios do estômago procedidos da corrupção dos mesmos alimentos e esta da influência da atmosfera".

As condições de higiene nas vilas também foram relatadas. Alexandre Rodrigues Ferreira registrava que em Barcelos, sede da capitania de São José do Rio Negro, a prática de enterrar cadáveres nas igrejas era prejudicial à saúde: "O terreno é muito úmido; e os cadáveres que nele se sepultam com dificuldade se consomem: donde procede, que para sepultar uns, vem a ser preciso descobrir outros", tornando intolerável a atmosfera particular da Igreja. Sendo assim, considerava-se conveniente "para conservação, não só da saúde dos vivos, como do repouso dos mortos", que se fizesse um cemitério público (Ferreira, 1983, p.312). Tais observações remetem a uma questão própria do saber médico do período, segundo o qual um dos principais meios de transmissão das doenças era a atmosfera corrompida pelos miasmas. Entre fins do século XVIII e ao longo do XIX, os médicos preocupavam-se com a questão dos focos de miasmas, e vários textos foram publicados acerca do assunto (Reis, 1991, p.252-254). Em 1798 uma comissão médica da Câmara do Rio de Janeiro alertava para a importância de resolver o problema. Dois anos depois, Vicente Coelho de Silva Teles, nascido nas Minas e graduado em filosofia em Coimbra, publicava a Memória sobre os prejuízos causados pelas sepulturas dos cadáveres dos templos e methodo de os prevenir (Silva, 1999, p.89). Entre aquilo que Corbin (1987) denominou "pólos de vigilância olfativa" e que demandava a atenção dos higienistas estavam as águas estagnadas, os odores dos excrementos, dos cadáveres e das carcaças de animais mortos, e a própria morte, que flutuava na atmosfera com o odor nauseabundo dos mortos. A própria terra, conforme se acreditava, era responsável por liberar odores morbíficos, daí o fato de as colônias do Novo Mundo, possuidoras de um solo inculto e selvagem, vitimarem com febres terríveis os colonos que nelas viviam (p.32-50). 
A maior parte das informações acerca das enfermidades não foi, entretanto, de responsabilidade de Rodrigues Ferreira. Este, pretendendo servir a "Sua Majestade e ao bem público", confiou tal missão a Antônio José de Araújo Braga, cirurgião formado em Coimbra e que exercera cirurgia no hospital de Cadiz, em Évora, e no Hospital Real de São José, de Lisboa. Na correspondência enviada ao cirurgião, em fevereiro de 1786, Alexandre Rodrigues Ferreira (1983, p.743) escrevia:

Achando-me encarregado por Sua Majestade da história filosófica e política dos estabelecimentos portugueses nesta capitania; e sendo aos seus habitantes universalmente constante a literatura e probidade com que Vmc. ... queira coadjuvar-me com as suas as minhas observações médicas, visto que a Vmc., mais privativamente que a mim, pertence uma escrupulosa averiguação de cada uma das enfermidades, suas causas, sintomas e prognósticos...

Observa-se que o perfil de Alexandre Rodrigues Ferreira não é somente o de um homem de ciência a serviço do conhecimento; trata-se também de um funcionário que deveria prestar todo tipo de informações à Coroa, o que reforça os aspectos pragmáticos do conhecimento produzido pelos letrados luso-brasileiros. Atendendo à solicitação de Alexandre Rodrigues Ferreira, Antônio José de Araújo Braga fornece inúmeras informações sobre as enfermidades mais comuns observadas nas povoações às margens do rio Negro: sarnas, pústulas, tosses convulsivas, cólera e febres. Em sua maioria eram provocadas pelos "miasmas podres de que a atmosfera se acha carregada", pelo calor da atmosfera quente e úmida e pelas águas estagnadas do rio (Ferreira, 1983, p.754-755).

No relato do cirurgião vem à tona, mais uma vez, a questão das doenças dos escravos. Ao adquirirem escravos que provinham de Cabo Verde, Angola e Benguela, os lavradores "não poucas vezes levam com eles para suas casas um contágio geral para todas as suas famílias" (Ferreira, 1983, p.754). Com base em constatações semelhantes às de José Vieira de Carvalho, Antônio José de Araújo Braga apontava diversas causas das doenças entre os cativos: "a má vida que levam sempre ocupados em violentos trabalhos", os "piores alimentos de que usam", e a "exposição do corpo ao ar ambiente", bem como o "uso das bebidas e dos licores espirituosos" (p.749). Chegava também às mesmas conclusões sobre a precariedade de alimentação da população da região do rio Negro. Afirmava que "a maior parte da plebe e dos escravos" alimentava-se de farinha, além de peixes "ardidos e podres", acusando os comerciantes de venderem alimentos estragados (p.755).

Um outro aspecto observado pelo cirurgião refere-se à higiene pública. Na cidade do Pará havia um açougue, "cujo sangue fica 
ali mesmo estagnado, além de se exporem os couros ao sol para se sujarem, e além de ficarem pelo pátio e pela praia adjacente as vísceras abdominais" dos animais mortos (p.754-755). A situação tão criticada pelas autoridades continuava, portanto, a ser um problema em fins do século XVIII.

O cirurgião informava ainda sobre a situação em que se encontrava a assistência médica. Prevalecia na capitania do Pará a atuação dos empíricos, que se constituíam árbitros da vida tendo como carta de aprovação a "credulidade da plebe". Embora criticasse o fato, Antônio José Braga afirmava que "a necessidade não tem lei e onde não há médico, nem cirurgião, melhor é sujeitar o enfermo ao curativo dos enfermeiros, que têm uma conhecida prática" (Ferreira, 1983, p.756). Dessa forma, acabava por valorizar o conhecimento dos empíricos, possuidores de informações acerca das virtudes curativas de diversas plantas que podiam vir a ser utilizadas em Portugal. Conforme recomendações de Alexandre Rodrigues Ferreira, Antônio José Braga passa então a descrever as plantas com propriedades terapêuticas, utilizadas para curar as mais diversas moléstias. Tal era o caso dos colírios preparados pela raiz do cipó chamado 'gapuhi', os remédios feitos com a 'folha do jambu' para dor de dente e os vermífugos preparados com o cozimento das folhas do 'mucurucabá' e de outra erva chamada 'crista de galo' (p.759-760). Esses conhecimentos se mostrariam úteis não apenas aos médicos e cirurgiões que atuavam na América portuguesa, mas também aos colonos que viviam em locais onde eram ausentes as boticas ou os remédios chegavam estragados. Além disso, inúmeras foram as remessas de ervas com propriedades farmacológicas para Portugal (Marques, 1999, p.97-141). As informações de Antônio José Braga foram incorporadas ao relatório de Alexandre Rodrigues Ferreira e se revelaram de extrema utilidade para o conhecimento das enfermidades comuns à região do Pará, bem como para o reconhecimento das propriedades terapêuticas de algumas plantas, propriedades essas que poderiam vir a ser aproveitadas no Reino.

Alguns estudos têm enfocado os limites da viagem de Alexandre Rodrigues Ferreira. Por um lado, os resultados da viagem filosófica do naturalista foram efêmeros, revelando certas debilidades da história natural em Portugal: o material da expedição - memórias, desenhos, relatos - permaneceu quase um século em manuscritos; os materiais enviados para Lisboa - plantas, animais e artefatos não foram estudados sequer pelo naturalista (Raminelli, dez. 1998). Houve também inabilidade estatal em coordenar e aplicar os conhecimentos proporcionados pela viagem do naturalista, de forma que suas observações não foram aproveitadas nas decisões político-administrativas de Portugal em relação ao Grão-Pará (Domigues, 2001, p.833). A pesar de tais aspectos, é inegável o significado 
simbólico que a viagem de Alexandre Rodrigues adquire para análise do papel que o conhecimento médico assumiu em fins do Setecentos na América portuguesa. Se levarmos em consideração os relatos do naturalista e do cirurgião Antônio José Braga, é possível afirmar que a questão das enfermidades que atingiam as populações da América portuguesa, incluindo os escravos, estava entre os assuntos que suscitavam demandas do governo português associadas à conservação da 'saúde dos povos'. Às informações produzidas pelo viajante devem ser acrescentadas as registradas por médicos e cirurgiões acerca das enfermidades dos negros e as obras destinadas a educar o povo na prevenção das doenças.

Com base na análise do quadro delineado por essas informações, torna-se evidente o fato de que a medicina desempenhou papel significativo para outras ciências, na constituição de informações sobre a América portuguesa. A renovação do conhecimento, forjada pela reforma do ensino da Universidade de Coimbra, e a criação de instituições de pesquisa como a Academia Real de Ciências de Lisboa, forneceram meios técnicos para as pesquisas a serem realizadas por cientistas e funcionários, entre os quais cartógrafos, naturalistas, médicos e cirurgiões, formando-se uma rede de informações destinada ao Estado português (Domingues, 2001). Conforme se procurou mostrar ao longo deste artigo, a medicina fazia parte desse processo.

\section{REFERÊNCIAS BIBLIOGRÁFICAS}

Almeida, Francisco José 1791

Araújo, Ana Cristina 1984

Ayres, José Ricardo de C. Mesquita nov. 2001

Bourguet, Marie-Noëlle 1997

Buchan, Guilherme 1788

Carvalho, Rómulo de 1987a

Carvalho, Rómulo de 1987b

Corbin, Alain 1987

Crespo, Jorge 1990
Tratado de educação fysica dos meninos para a nação portuguesa. Lisboa: Officina da Academia Real de Ciências.

Ilustração, pedagogia e ciência em Antônio Nunes Ribeiro Sanches. Revista de História e Teoria das idéias, Coimbra, v.6, p.377-395.

A saúde coletiva e o espaço público moderno: raízes histórico-sociais da ciência epidemiológica. Projeto História, São Paulo, n.23, p.83-103.

O explorador. In: Vovelle, Michel.

O homem do Iluminismo. Lisboa: Presença. p.207-249.

Medicina doméstica ou tratado completo dos meios de conservar a saúde e de curar. t.I. Lisboa: Typografia Rollandiana.

História do ensino em Portugal: desde a fundação da nacionalidade até o fim do regime de Salazar-Caetano. Lisboa: Calouste Gulbenkian.

A história natural em Portugal no século XVIII. Lisboa: Instituto de Cultura e Língua Portuguesa/Ministério da Educação. (Biblioteca Breve, 112).

Saberes e odores: o olfato e o imaginário social nos séculos dezoito e dezenove. São Paulo: Companhia das Letras.

A história do corpo.

Lisboa: Difel, 1990. 
Dazille, Jean-Barthélemy 1801

Dias, Maria Odila da 1969

Domingues, Ângela 2001

Estatutos... 1972

Falcon, Francisco José Calazans 1982

Ferreira, Alexandre Rodrigues 1983

Ferreira, Luís Gomes 2002

Foucault, Michel 2001

Franco, Francisco de Mello 1790

Henriques, Francisco da Fonseca 2004

Inventário... jul.-dez. 1905

Kury, Lorelai

2004

Leitão, Manoel José 1788

Marques, Vera Regina Beltrão

2004

Marques, Vera Regina Beltrão

1999

Marquese, Rafael de Bívar

2004

Maxwell, Kenneth 1996

Pimenta, Tânia Salgado 2003
Observações sobre as enfermidades dos negros, suas causas, seus tratamentos, e os meios de as prevenir. Trad. Antonio José Vieira de Carvalho. Lisboa: Typografia chalcográfica, typoplástica, e literária do Arco do Cego.

Aspectos da Ilustração no Brasil. Revista do Instituto Histórico e Geográfico Brasileiro, Rio de Janeiro, n.278, p.105-170.

Para um melhor conhecimento dos domínios coloniais: a constituição de redes de informação no Império Português em finais do Setecentos. História, Ciências, Saúde - Manguinhos, Rio de Janeiro, v.8, supl., p.823-838.

Estatutos da Universidade de Coimbra de 1772: cursos das sciencias naturaes e filosóficas. livro III. Coimbra: Ed. da Universidade. Edição fac-símile.

A época pombalina: política econômica e monarquia ilustrada.

São Paulo: Ática.

Viagem filosófica ao Rio Negro.

Belém: Museu Paraense Emílio Goeldi.

Erário mineral.

Belo Horizonte: Fundação João Pinheiro.

O nascimento da clínica.

Rio de Janeiro: Forense Universitária.

Tractado de educação fysica dos meninos, para uso da nação portuguesa. Lisboa: Officina da Academia Real das Sciencias de Lisboa.

Âncora medicinal para conservar a vida com saúde.

São Paulo: Ateliê Editorial. 1a. ed., 1721.

Inventário dos bens móveis de Antônio José Vieira de Carvalho, capitão cirurgião mor deste regimento de Cavalaria de Linha de Minas Gerais. Revista do Arquivo público mineiro, Belo Horizonte, v.10, fasc. III-IV, p.706-709.

Homens de ciência no Brasil: impérios coloniais e circulação de informação (1780-1810). História, Ciências, Saúde - Manguinhos, Rio de Janeiro, v.11, supl. 1, p.109-129.

Tratado completo de anatomia e cirurgia com um resumo da história da anatomia e cirurgia, seus progressos e estado dela em Portugal offerecido à Real Junta do Protomedicato. Lisboa: Antonio Gomes.

Instruir para fazer a ciência e a medicina chegar ao povo no Setecentos. Vária História. Belo Horizonte, n.32, p.37-47.

Natureza em boiões: medicinas e boticários no Brasil setecentista. Campinas: Ed. Unicamp.

Feitores do corpo, missionários da mente: senhores, letrados e o controle dos escravos nas Américas, 1660-1680. São Paulo: Companhia das Letras.

Marquês de Pombal: paradoxo do Iluminismo.

Rio de Janeiro: Paz e Terra.

Terapeutas populares e instituições médicas na primeira metade do século XVIII. In: Chalhoub, Sidney et al. (Org.). Artes e ofícios de curar no Brasil. Campinas: Ed. Unicamp. p.307-330. 
Pita, João Rui

1999

Pita, João Rui 1996

Raminelli, Ronald dez. 1998

Reis, João José 1991

Ribeiro, Márcia Moisés 1997

Sanches, Antônio

Nunes Ribeiro 1757

Silva, Maria Beatriz Nizza da

1999

Tissot

1773

Villalta, Luiz Carlos 1999
Um livro de 200 anos: a Farmacopéia portuguesa (Edição oficial). A publicação da primeira farmacopéia oficial: Pharmacopeia Geral (1794). Revista de História das idéias, Coimbra, v.20, p.131-147.

Farmácia, medicina e saúde pública em Portugal (1772-1836).

Coimbra: Livraria Minerva.

Ciência e colonização: viagem filosófica de Alexandre Rodrigues Ferreira. Tempo, Rio de Janeiro, v.3, n.6, p.157-182.

A morte é uma festa: ritos fúnebres e revolta popular no Brasil do século XIX. São Paulo: Companhia das Letras.

A ciência dos trópicos: a arte médica no Brasil do século XVIII. São Paulo: Hucitec.

Tratado da conservação da saúde dos povos: obra útil, e igualmente necessária aos magistrados, capitães generais de mar, e guerra, prelados, abadessas, médicos e pais de família com um apendix: considerações sobre os terremotos, com a notícia dos mais consideráveis de que faz menção a história, e dos últimos que faz menção a história, e dos últimos que se sentiram na Europa desde I de Novembro de 1755. Lisboa: Officina Joseph Filipe.

A cultura luso-brasileira: da reforma da universidade à independência do Brasil. Lisboa: Estampa.

Aviso ao povo sobre a sua saúde. t.I. Lisboa: Officina Patriarcal, t.I.

Reformismo ilustrado, censura e práticas de leitura: usos do livro na América portuguesa. Tese (Doutorado) - Faculdade de Filosofia, Letras e Ciências Humanas, Universidade de São Paulo, São Paulo.

Recebido para publicação em maio de 2005.

Aprovado para publicação em fevereiro de 2006. 